\title{
Functional Specificity of a Long-range Horizontal Connection in Cat Visual Cortex: A Cross-correlation Study
}

\author{
Cornelius Schwarz and Jürgen Bolz \\ Friedrich-Miescher-Labor der Max-Planck-Gesellschaft, Tübingen, Germany
}

\begin{abstract}
Anatomical investigations of the visual cortex revealed a regular set of interlaminar connections and long-range horizontal connections. An important component of the intrinsic cortical circuit is the projection from layer 5 to layer 6 over long horizontal distances. Previous work has shown that when layer 5 is locally inactivated, layer 6 cells lose their response in a segment of their receptive fields corresponding to the blocked area in layer 5 . It has therefore been proposed that the long receptive fields characteristic of layer 6 cells might be generated by concatenating layer 5 cells with similar orientation preferences. In the present study, we used cross-correlation analysis to examine both source and target cells of the interlaminar connection from layer 5 to layer 6 . We found correlated firing between cells separated by up to $4.2 \mathrm{~mm}$, the longest horizontal distance studied. The occurrence of correlated firing depended on the functional properties and on the topographic position of the cells in layer 5 and layer 6 . Interactions were only observed if the cells had matching orientation tuning and similar eye preference and if the layer 5 cells lay within the summation area of the layer 6 cells. Both simple and complex cells in layer 6 fired in synchrony with layer 5 cells. In layer 5, mainly standard complex cells, but very few special complex cells, participated in correlated firing with layer 6 cells. These results suggest that cells in layer 6 receive their input from cooriented, coaxially aligned standard complex cells in layer 5. This topographic arrangement and the length summation properties of standard complex cells in layer 5 are well suited to generate long receptive fields in layer 6 . Thus, our experiments provide evidence for the functional specialization of a particular component of cortical circuitry.
\end{abstract}

Cells in the visual cortex have specialized functional properties designed to analyze the signals coming from the retina. Because cortical neurons have more complex and more diverse receptive field features than their input cells, many of these properties must be generated within the cortex. Knowledge of intrinsic

\footnotetext{
Received Feb. 27, 1991; revised May 2, 1991; accepted May 7, 1991.

We thank Ad Aertsen for valuable discussions and generously making available to us his software for normalization of the cross-correlograms. Kaare Christian did the programming of the software for data acquisition and designed the comlputer-controlled optical bench. Advisory help for the application of multivariate statistics was provided by Klaus Dietz from the Institut für medizinische Biometric, Tübingen. We also thank Jerry Nelson, Mark Hübener, and Nicls Adams for many helpful comments on the manuscript, and Iris Kehrer for her reliable technical assistance.

Correspondence should be addressed to Jürgen Bolz, Friedrich-Miescher-Labor der Max-Planck-Gesellschaft, Spemannstrasse 37-39, 7400 Tübingen, Germany. Copyright (c) 1991 Society for Neuroscience $0270-6474 / 91 / 112995-13 \$ 05.00 / 0$
}

cortical connections is a basic requirement for understanding the mechanisms of receptive field generation. Golgi stainings and intracellular dye injections have revealed a series of regular connections between cortical layers (Ramón y Cajal, 1921; Lorente de Nó, 1933; Gilbert and Wiesel, 1979; Lund et al., 1979; Martin and Whitteridge, 1984). In addition to these interlaminar connections, there are long-ranging horizontal connections running parallel to the cortical surface (Rockland and Lund, 1982; Gilbert and Wiesel, 1983).

On the basis of the detailed information about particular connections, it is possible to dissect the cortical circuitry and to examine functional correlates of cortical connections. One approach has been to block the action of a neurotransmitter and to study its effect on the response characteristics of cortical cells. For example, when inhibitory transmitter GABA is blocked by iontophoretical application of the GABA antagonist bicuculline, cells become less selective for the orientation and the motion direction of a stimulus (see Sillito, 1984). However, GABAergic cells are found in many different cell types, and they are located in all cortical layers (Ribak, 1978; Somogyi et al., 1981), rendering it difficult to attribute receptive field properties to particular classes of GABAergic cells. A more direct way to analyze the cortical circuit is to inactivate pharmacologically the neurons that give rise to a particular pathway and to observe the effect of the inactivation on the response properties of the recipient cells (see Bolz et al., 1989). These experiments attempted to associate individual cortical connections to specific functional properties, such as end-inhibition, receptive field size, directionality, and receptive field type (Bolz and Gilbert, 1986, 1989; Schwark et al., 1986; Eysel et al., 1987).

A prominent example of a cortical connection with long horizontal spread is the projection of layer 5 pyramidal cells, which have axon collaterals extending for several millimeters into layer 6 (Gilbert and Wiesel, 1983; Martin and Whitteridge, 1984; Hübener et al., 1990). Local inactivation of layer 5 blocked the visual responses of layer 6 cells in a segment of their receptive fields corresponding to the inactivated region of layer 5 (Bolz and Gilbert, 1989). This effect was seen when the layer 6 cells were horizontally displaced by up to $3 \mathrm{~mm}$ from the inactivated area in layer 5 . It has therefore been proposed that the projection from layer 5 to layer 6 generates the long receptive fields of layer 6 cells, which are a characteristic feature of the cells in this layer. However, such a scheme would require a highly specific wiring between cells in layer 5 and layer 6 : layer 5 cells projecting into layer 6 would have to target cells with matching orientation preference and visuotopically aligned receptive fields. With the inactivation method, it is difficult to characterize the presynaptic site of a cortical connection, since all neurons within this cortical region are silenced. Therefore, in the present study 


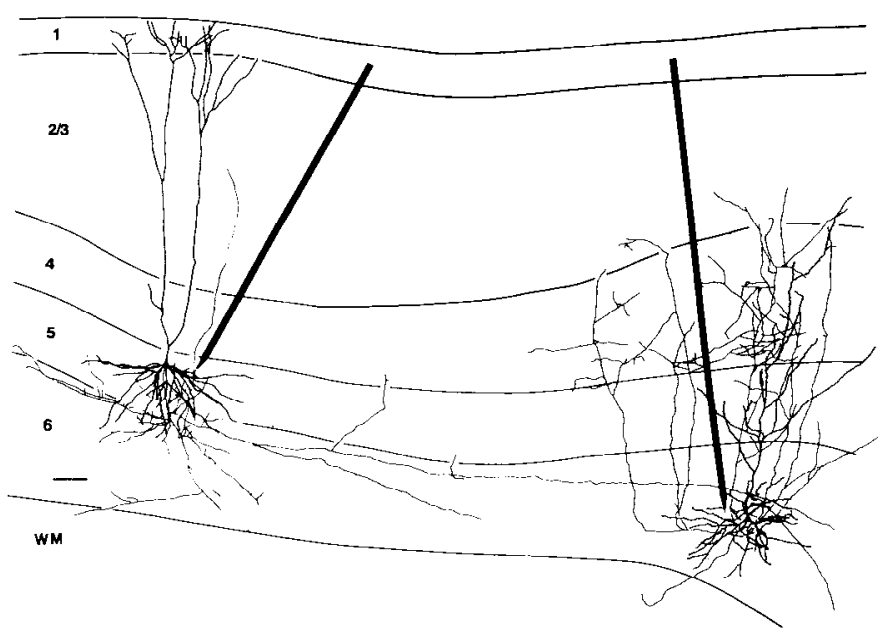

Figure 1. Compositc drawing of intraccllularly staincd ncurons in laycr 5 and layer 6 to illustrate the experimental approach (adapted from Hübener et al., 1990). As is characteristic for cells in this layer, the neuron in layer 5 has axon collaterals that project over long distances into layer 6 . In the present study, simultaneous extracellular recordings were made with two electrodes, one placed in layer 5 and one in layer 6 , and the cross-correlation analysis was used to detect interaction between the cells.

we recorded simultaneously from individual neurons in layer 5 and layer 6 and used cross-correlation analysis to study the interaction between source and target cells of this interlaminar connection. Our results suggest that the projection from layer 5 to layer 6 meets the requirements for constructing the long receptive fields of layer 6 cells.

\section{Materials and Methods}

Experiments were performed on 23 adult cats of both sexes. The animals were initially anesthetized with an intramuscular injection of a mixture of ketamine $(20 \mathrm{mg} / \mathrm{kg})$ and $0.2 \mathrm{ml}$ altropin sulfate $(1 \mathrm{mg} / \mathrm{ml})$, intubated with an endotracheal tube, and put into a stereotaxic headholder. They were then paralyzed with pancuronium bromide $(0.3 \mathrm{mg} / \mathrm{kg} / \mathrm{hr}, \mathrm{i} . \mathrm{v}$. $)$ and respirated artificially with a mixture of $30 \%$ oxygen and $70 \%$ nitrous oxide. Respiration was adjusted to an end-expiratory $\mathrm{CO}_{2}$ level of $4 \%$. Rectal temperature was maintained at $37.8^{\circ} \mathrm{C}$. Electrocardiogram (ECG) and electroencephalogram (EEG) were recorded throughout the experiment with a patient monitor (Hewlett Packard). Halothane $(0.2-0.5 \%)$ was administered according to EEG and ECG to ensure adequate level of anesthesia. The nictating membrane was retracted with Neo-Synephrine $(1 \%)$, and the pupils were dilated with atropine sulfate $(1 \%)$. Appropriate contact lenses were used to focus the eyes onto a tangent screen $1.72 \mathrm{~m}$ in front of the animal. The area centralis was plotted onto the screen by means of a Zeiss fundus camera. A hole, about 4 $\mathrm{mm}$ in diameter, was drilled into the skull, and the dura was opened to allow insertion of two etched lacquer-coated tungsten electrodes (Hubel, 1957) into area 17. Routinely, four such trepanations were made during an experiment above the part of area 17 representing the central visual area in both hemispheres (maximum eccentricity, $15^{\circ}$ ). The trepanation was covered with agar (3\% in saline) in order to reduce pulsations of the brain. The edges of the wound were periodically infiltrated with the local anesthetic bupivacaine hydrochloride (Carbostesin Astra; $0.25 \%$ ).

The experimental approach is illustrated schematically in Figure 1. Two electrodes, displaced in anteroposterior direction, were placed into layers 5 and 6 , respectively, with the aid of a microstepper motor (Oriel; step size, $1 \mu \mathrm{m}$ ). The appropriate layers were found by determining the receptive field properties of cells at different depths (see below). Tracks were marked with several small electrolytic lesions ( $4 \mu \mathrm{A}$ for $4 \mathrm{sec}$, tip negative; lesion diameter, approximately $100 \mu \mathrm{m}$ ) to verify the laminar positions and the displacement of the electrodes. At the end of an experiment, the cat was deeply anesthetized and then perfused through the heart with a preflush consisting of $50 \mathrm{gm}$ sucrose, $5 \mathrm{mg}$ lidocaine, and $0.28 \mathrm{mg}$ heparin in $110.1 \mathrm{M}$ phosphate buffer $(\mathrm{PB})$, followed by $4 \%$ paraformaldehyde in PB. Blocks of tissue containing the electrode tracks were removed and postfixed overnight. The tissue was immersed in $30 \%$ sucrose/PB and sectioned on a freezing microtome (Reichert and Jung; thickness, $60 \mu \mathrm{m}$ ) and stained with cresyl violet. Tracks were reconstructed with the aid of the electrolytic lesions, and cortical layers were determined using the criteria of Otsuka and Hassler (1962). In one animal, shrinkage of the tissue during staining was assessed by making four lesions at $1 \mathrm{~mm}$ distance. The tissue shrank in linear dimensions by a factor of 0.7 . The intercellular distances measured in the histological reconstructions of the electrode tracks were therefore multiplied by a factor of 1.4 to correct for the shrinkage of the tissue.

Receptive field properties. Layer 5 neurons were identified by their large complex receptive field, high spontaneous activity, and brisk response characteristics. Typically, they can be driven by either eye, and most cells show directional preference (Palmer and Rosenquist, 1974; Gilbert, 1977; Henry et al., 1979). Cells in layer 6 are characterized by their very long receptive fields: for optimal stimulation they require a bar that is three to six times longer than the receptive field of the layer 5 cells. A particular feature of these cells is that they do not respond to short bars or to long bar stimuli excluding their receptive field center (Gilbert, 1977).

The optimal orientation and limits of response were assessed by stimulating the cells with bars of different orientation. The bisector of the angle between the two limiting orientations was taken as the optimal orientation. Flashes of light bars were used to test for stationary on/off responses of the cells at different positions within their receptive field. Cells were classified as simple if their receptive field displayed separate on and off response regions; otherwise they were classified as complex (Hubel and Wiesel, 1962). The receptive fields of layer 5 neurons were mapped using the minimal response method introduced by Barlow et al. (1967). With this method, the borders of the receptive field were determined using short, optimally oriented stimuli swept across and beside the receptive field. For layer 6 cells, light bars of different length were used to estimate the extent of their length summation.

Layer 5 cells were classified further according to the summation properties along the orientation axis. Cells summing up the entire length of their receptive field were classified as standard complex. Cells responding optimally to a small bar projected anywhere into their receptive field and showing no summation with longer bars were classified as special complex (Gilbert, 1977).

Cells were also grouped into ocular dominance classes 1-7 according to Hubel and Wiesel (1962) and classified with respect to the strength of directionality and end-inhibition. Class 0 comprises cells with no detectable directional preference or end-inhibition, whereas cells with complete direction selectivity (no response in null direction) or endinhibition (no response to a long bar) were put into class 3 . Classes 1 and 2 signify moderate and strong directionality or end-inhibition, respectively.

We first mapped the receptive field properties using a hand-held projector. In several cases, orientation and length tuning curves were measured from response histograms to verify the mapping by hand. For this, a computer-controlled optomechanical bench was used to generate the light bars (stimulus luminance, $11.0 \mathrm{~cd} / \mathrm{m}^{2}$; background luminance, $\left.1.0 \mathrm{~cd} / \mathrm{m}^{2}\right)$. The extracellularly recorded potentials were amplified and fed into Schmitt triggers, whose pulses were sampled with an I/O port in a computer at a rate of $10 \mathrm{kHz}$. Analog signals, thresholds, and output pulses were continuously monitored to ensure stable single-unit recordings.

Cross-correlation analysis. For cross-correlation analysis, both cells were usually driven with a light bar presented monocularly. In a few cases, the cells were stimulated binocularly. When a single stimulus elicited only weak responses from the cells, two different bars were used for optimal stimulation of each cell. In some cascs, both optimal and suboptimal stimuli were applied. The time required to sample a minimum of 2000 spikes (in most cases far more) from each cell ranged between 15 and $30 \mathrm{~min}$.

Cross-correlograms were calculated in two ways. For on-line display, the computer calculated time differences between all possible spike pairs of the two spike trains within a 150 and $500 \mathrm{msec}$ window. The histograms of these time differences (one for each window) represent the raw cross-correlogram: the zero bin indicates how often the two cells fired at the same time, and the positive/negative values represent the various time intervals that one cell fired before/after the other cell. To estimate the correlated firing due to the simultaneous stimulation of the two cells (stimulus coordination artifact), off line, one spike train was shifted by one stimulus period and the cross-correlogram was recom- 


\begin{tabular}{|c|c|c|}
\hline Variable & Value & Description \\
\hline \multirow[t]{2}{*}{$\bar{A}$} & 1 & $\begin{array}{l}\text { Matching orientation preference, } \\
\text { (difference, } \leq 30^{\circ} \text { ) }\end{array}$ \\
\hline & 0 & $\begin{array}{l}\text { Nonmatching orientation preference } \\
\left(\text { difference, }>30^{\circ} \text { ) }\right.\end{array}$ \\
\hline \multirow[t]{2}{*}{$B$} & 1 & Overlapping receptive fields \\
\hline & 0 & Nonoverlapping receptive fields \\
\hline \multirow[t]{2}{*}{$C$} & 1 & Standard complex receptive field in layer 5 \\
\hline & 0 & Special complex receptive field in layer 5 \\
\hline \multirow[t]{2}{*}{$D$} & 1 & Peaked cross-correlogram \\
\hline & 0 & Flat cross-correlogram \\
\hline
\end{tabular}

For statistical analysis, all cell pairs were grouped according to the four binary variables: $A$, orientation preference; $B$, receptive field topography; $C$, receptive field type in layer 5 ; and $D$, coherent firing. Each variable may assume the values " 0 " and " 1 ." Values of each variable and a description are given. Note that the variables are nominal in character. Thus, in the analysis the values " 0 " and " 1 " were not interpreted quantitatively.

puted. Subtraction of this "shift-predictor" from the raw cross-correlogram yields the shift-corrected cross-correlogram where the stimulus artifact should be eliminated (Perkel et al., 1967). All cross-correlograms shown in this article are shift-corrected cross-correlograms.

As the raw- and shift-corrected cross-correlograms are dependent on the sampling time and the firing rates of the cells, the peaks in the crosscorrelograms of different pairs are not directly comparable. To derive cross-correlograms that are independent of these parameters, we used a normalization procedure developed by Aertsen et al. (1989). This method is based on the joint peristimulus time histogram where correlated firing of two cells appear as a diagonal feature (see also Gerstein and Perkel, 1972). We took the area below the central peak in the normalized cross-correlograms as a measure for the correlated firing between the two cells under study. This measure was obtained by the sum of the bins in the normalized joint peristimulus time histogram [see Eq. 9 of Aertsen et al. (1989)] that correspond to the diagonal feature of the peak. As all peaks in our cross-correlograms were symmetrical to the zero bin and were not broader than $15 \mathrm{msec}$, a cell pair was classified as "peaked" if the area below a visible peak or the central 15 msec exceeded 0.04 and if clear diagonal patterns in the normalized joint poststimulus time histogram could be detected.

Statistical analysis. The cell pairs were classified according to the four variables "orientation preference" $(A)$, "receptive field topography" $(B)$, "receptive field type in layer 5" $(C)$, and "coherent firing" $(D)$ (Table 1). Ten cell pairs in which the receptive field type of the layer 5 cell was not identified were excluded from the analysis. In order to estimate the effects of the variables $A, B$, and $C$ on the coherent firing (variable $D$ ), we fitted a logistic model to the data (Cox, 1970; Software package JMD, SAS Institute Inc.). This model quantitatively describes the effects of the independent variables $A, B$, and $C$ on the dependent variable $D$ according to the formula

$$
\ln (y / 1-y)=\beta_{0}+\beta_{1} x_{1}+\beta_{2} x_{2}+\beta_{3} x_{3},
$$

where $y$ is the probability to get coherent firing; $x_{1}, x_{2}$, and $x_{3}$ signify the properties of the variables $A, B$, and $C ; \beta_{0}$ is a constant; and $\beta_{1}, \beta_{2}$, and $\beta_{3}$ signify the effects of the variables $A, B$, and $C$ upon $D$.

\section{Results}

Cross-correlograms were obtained from 122 cell pairs, each with one cell in layer 5 and one cell in layer 6 . The pairs comprise 82 cells recorded in layer 5 and 98 cells recorded in layer 6; thus, some cells were used in more than one pair for crosscorrelogram analysis.

\section{Physiological properties of cells in layers 5 and 6}

All cells in layer 5 had complex receptive fields, and 61 cells were classified as standard complex and 12 cells as special complex. Nine layer 5 cells remained unclassified: their length summation characteristics could not be determined unequivocally with the hand-held projector, and they were lost before length tuning curves were completed. Of the layer 6 cells, 24 had simple and 72 had standard complex receptive fields; 2 cells remained unclassified. No special complex cells were found in layer 6 .

In accordance with earlier studies (Palmer and Rosenquist, 1974; Gilbert, 1977; Leventhal and Hirsch, 1978; Harvey, 1980), we found that layer 5 and layer 6 neurons display different ocular dominance and directionality preference. These results are summarized in Table 2. Cells in layer 5 cells were more often binocular than cells in layer 6: 79\% of the layer 5 cells could be well driven via both eyes (ocular dominance classes 3, 4, and 5 ); in layer 6 only $59 \%$ fell into these classes. On the other hand, only $2 \%$ of the layer 5 cells were strongly monocular, whereas $13 \%$ of the layer 6 neurons could be stimulated via one eye exclusively (classes 1 and 7).

Cells in layer 5 more often preferred one direction of stimulus movement compared to cells in layer 6 . Of our layer 5 cells,

Table 2. Ocular dominance and directionality of cells in layers 5 and 6

\begin{tabular}{llcl} 
Measurement & Class & Layer 5 & Layer 6 \\
\hline Ocular dominance & 4 & $38(45 \%)$ & $23(29 \%)$ \\
& 3,5 & $29(34 \%)$ & $24(29 \%)$ \\
& 2,6 & $16(19 \%)$ & $23(29 \%)$ \\
Directionality & 1,7 & $2(2 \%)$ & $10(13 \%)$ \\
& Total & $85(100 \%)$ & $80(100 \%)$ \\
& 0 & $29(31 \%)$ & $41(48 \%)$ \\
& 1 & $29(31 \%)$ & $21(24 \%)$ \\
& 2 & $26(28 \%)$ & $17(20 \%)$ \\
& 3 & $9(10 \%)$ & $7(8 \%)$ \\
& Total & $93(100 \%)$ & $86(100 \%)$
\end{tabular}




\section{Peak area}

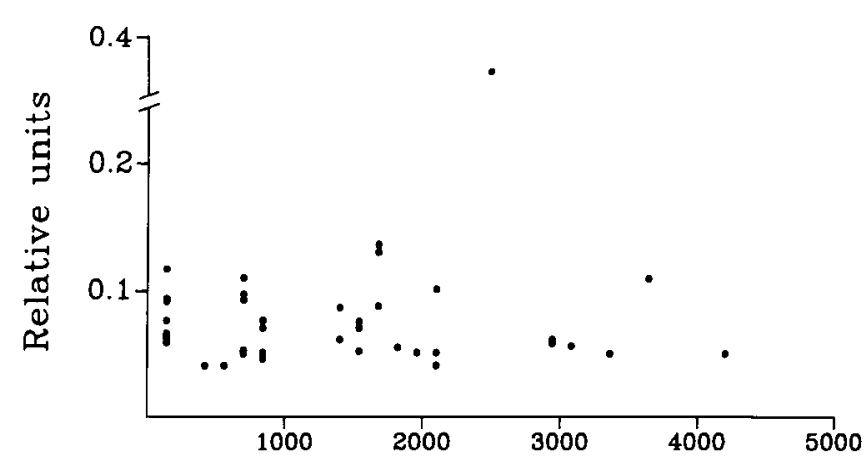

Peak width

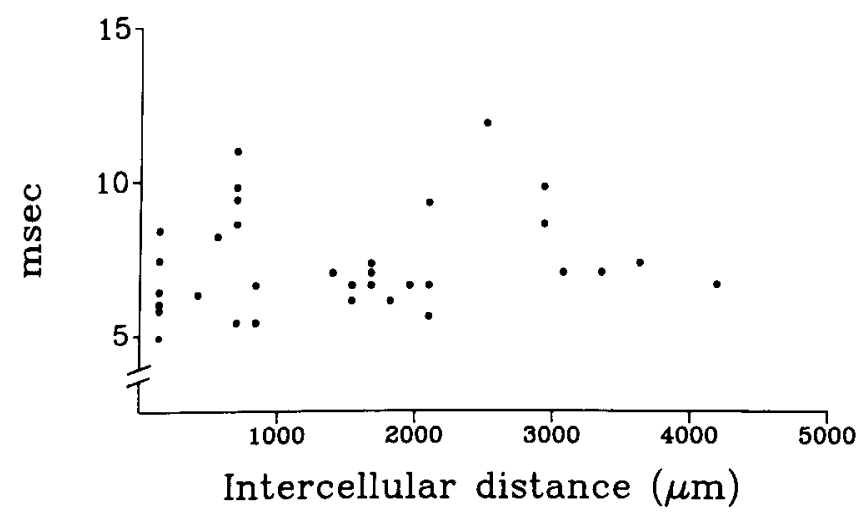

Figure 2. Area below the peaks (top) and width at half peak height (bottom) in the normalized cross-correlograms plotted against the intercellular distance. All cell pairs with a peaked cross-correlogram were included $(n=38)$.

$69 \%$ were directional (classes 1, 2, and 3); in layer 6 this was truc only for $52 \%$ of the cells. End-inhibited cells were only found in layer 5 ; no cell in layer 6 displayed this receptive field property. As shown in Table 3, special complex cells in layer 5 are more strongly end-inhibited than standard complex cells.

\section{Cross-correlograms}

Most cross-correlograms were flat ( 84 out of 122 ); the remaining 38 cross-correlugrams showed a peak according to the criteria described in Materials and Methods. The peaks were exclusively of the common input type straddling the zero bin (Perkel et al., 1967). Figure 2 depicts the area below the peaks and the peak width at half-height as a function of the spacing of the cell pairs. There was no obvious change of either parameter with the intercellular distance.

Orientation preference. As was found previously for cells in the superficial layers (Ts'o et al., 1986), peaked cross-correlograms between cells in layer 5 and layer 6 were observed predominantly if the cells had similar orientation preferences. Figure 3 shows two cell pairs, where each layer 5 cell and each layer 6 cell had a standard complex receptive field and similar ocular dominance and directional preference. In both cases, the receptive field of the layer 5 cell completely overlapped with the receptive field of the layer 6 cell. The cells in the upper part of
Table 3. End-inhibition of layer 5 cells

\begin{tabular}{llc} 
& \multicolumn{2}{l}{ Receptive field type } \\
\cline { 2 - 3 } End-inhibition & $\begin{array}{l}\text { Standard } \\
\text { complex }\end{array}$ & $\begin{array}{l}\text { Special } \\
\text { complex }\end{array}$ \\
\hline 0 & $45(68 \%)$ & $7(41 \%)$ \\
1 & $13(20 \%)$ & $5(29 \%)$ \\
2 & $6(9 \%)$ & $1(6 \%)$ \\
3 & $1(2 \%)$ & $4(24 \%)$ \\
Total & $65(100 \%)$ & $17(100 \%)$
\end{tabular}

In addition to the layer 5 neurons used for cross-correlation analysis, the number of all layer 5 cells analyzed for receptive field type and end-inhibition is listed.

Figure 3 had matching orientation preferences (difference, $9^{\circ}$ ), and their cross-correlogram showed a prominent common input peak. In contrast, the orientation preferences of the cells in the pair shown in the lower part of Figure 3 differed by $74^{\circ}$, and their cross-correlogram was flat.

Of the 38 peaked cross-correlograms we obtained, 30 cell pairs had similar orientation tuning $\left(0-30^{\circ}\right.$ difference $), 7$ pairs differed by $31-60^{\circ}$, and 1 cell pair differed by $80^{\circ}$. In 6 out of the 8 peaked cross-correlograms with different orientation preferences for the two cell pairs $\left(>30^{\circ}\right)$, the cells were less than 1 $\mathrm{mm}$ apart. Thus, the tendency to fire coherently with matching orientation preference is more pronounced for cells separated by long horizontal distances.

Within our total sample, we found approximately equal amounts of peaked ( $n=30)$ and flat $(n=29)$ cross-correlograms among the cell pairs with matching orientation preferences (Fig. 4). Thus, matched orientation preference is a facilitating, but not a sufficient, condition for correlated firing between layer 5 and layer 6 cells. As will be shown below, other necessary conditions for coincident firing between a cell in layer 5 and layer 6 are that the layer 5 cell have a standard complex receptive field and that their receptive fields overlap. If we select only those cell pairs where these conditions are met, then 26 out of 30 cell pairs with matching orientation preferences have peaked cross-correlograms (Fig. 4).

Ocular dominance, directionality, and end-inhibition. Peaked cross-correlograms were obtained with monocular and binocular cells in both layers. To examine whether similar eye preferences are critical for coherent firing, we computed the difference of the ocular dominance class for each cell pair (Table 4). There was a tendency to fire correlated when the two cells had similar eye preference: in all cases where the two cells differed by more than two ocular dominance classes, the cross-correlograms were flat.

Cells with directional preference, as well as cells that responded equally to both directions of the stimulus were found among the cells with peaked cross-correlograms. In order to test whether synchronous firing depends on matching directional preferences, we selected cell pairs where both cells were directionally biased (classes 1-3) and had similar orientation preferences. As shown in Table 4, 12 out of 16 cell pairs with same directionality, but only 1 out of 4 pairs with opposite directional preference, fired coherently. Although our sample of cell pairs with oppositc directionality is small, there seems to be a tendency to fire coherently predominantly if the cells prefer the same direction of stimulus movement.

No consistent relationship between the degree of end-inhibition of layer 5 cells and their correlated firing behavior with layer 6 cells could be detected (Table 4). 

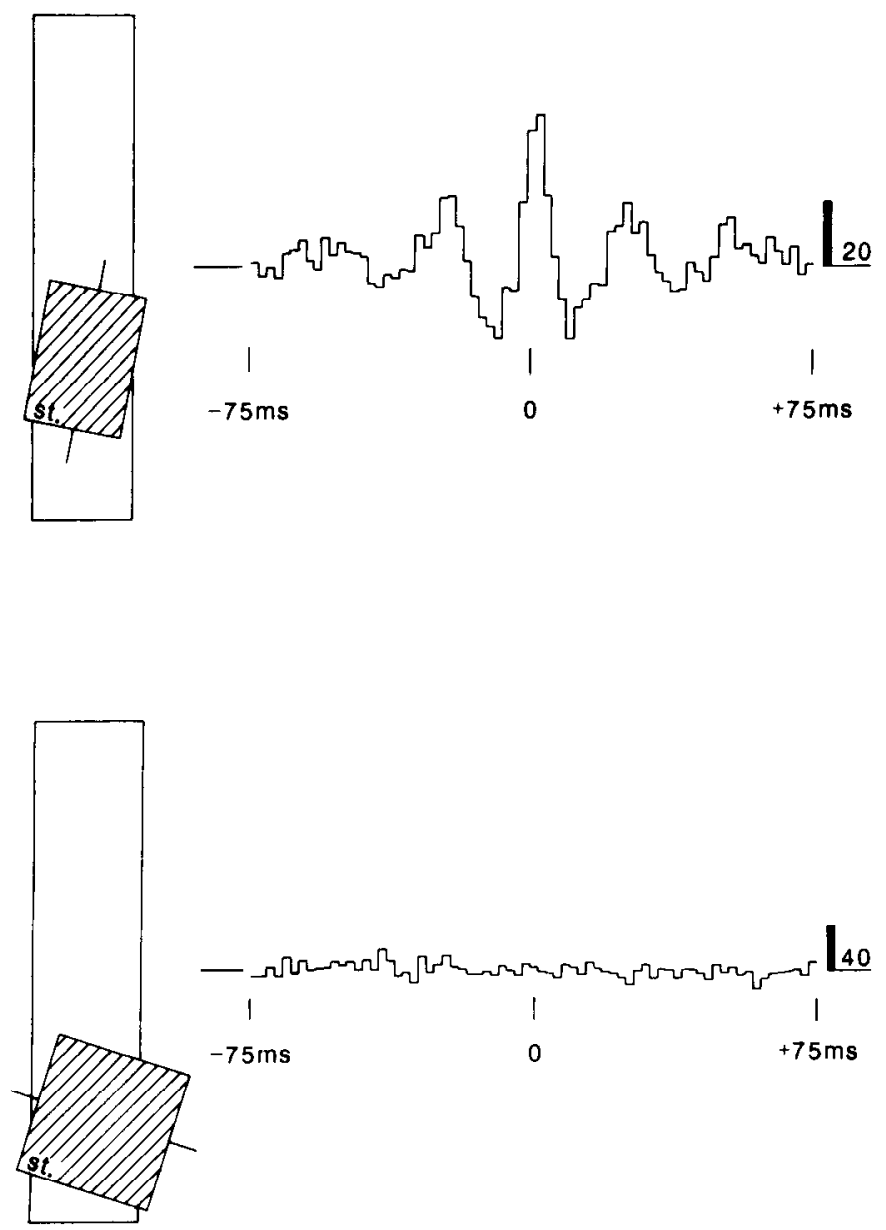

Figure 3. Shift-corrected cross-correlograms demonstrating the dependency of coherent firing on matching orientation preference. Top, Two standard complex (st.) cells separated by $1.7 \mathrm{~mm}$ were recorded simultaneously in layer 5 and layer 6 . As shown on the left, the receptive field of the layer 5 cell (cross-hatched box) overlapped with the receptive field of the layer 6 cell (open box). The cells had matching orientation preference (difference, $9^{\circ}$ ). The central peak in the cross-correlogram (right) indicates coherent firing of the two cells (peak width at halfheight, $7 \mathrm{msec}$ ). Note additional side peaks separated from the central peak by $25 \mathrm{msec}$. Size of receptive field of layer 5 cell, $1^{\circ} \times 2^{\circ}$; eccentricity, $5^{\circ}$; one bar stimulus of optimal orientation. Bottom, In this pair, the cell in layer 5 and the cell in layer 6 were both classified as standard complex; they were separated by $0.8 \mathrm{~mm}$ and had overlapping receptive fields. In contrast to the example shown above, their orientation prefcrences did not match (difference, $7^{\circ}$ ). The flat cross-correlogram indicates that the cells fired independently from each other. Size of receptive field of layer 5 cell, $2^{\circ} \times 2^{\circ}$; eccentricity, $8^{\circ}$; one bar stimulus. Calibration: bin width, $2.1 \mathrm{msec}$; vertical scale bars on the right indicate number of counts. To simplify the drawings, the receptive fields of the layer 6 cells were always oriented vertically.

Receptive field topography. Correlated firing depended on the relative position of the receptive fields of the layer 5 and layer 6 cells: 36 out of 38 cell pairs with peaked cross-correlograms had overlapping fields. An example of this finding is illustrated in Figure 5. Both cells in the upper part of the figure had matching orientation tuning (difference, $10^{\circ}$ ), were standard complex, fell in ocular dominance group 6, and preferred the same stimulus direction. The receptive field of the layer 5 cell lay within the summation area of the layer 6 cell. As indicated by the crosscorrelogram, the two cells exhibited strong correlated firing. The cell pair shown in lower Figure 5 also consisted of standard

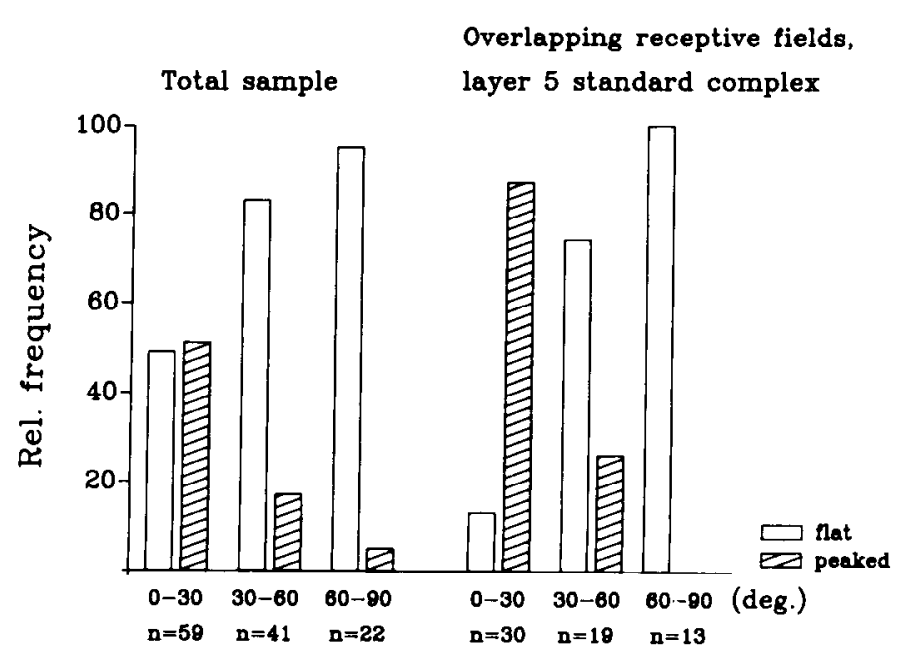

\section{Difference in orientation preference}

Figure 4. Histogram displaying the proportion of flat and peaked crosscorrelograms between cells in layer 5 and layer 6 for various differences in orientation preferences. The left part of the figure shows all cell pairs analyzed; the right part depicts only pairs with overlapping receptive fields and with layer 5 standard complex cell.

complex cells with matching orientation preference (difference, $3^{\circ}$ ) and similar ocular dominance group, and both cells exhibited direction preference to stimuli moving to the left. However, the receptive field of the layer 5 cell did not lie within the summation area of the layer 6 cell. No sign of correlated firing between these cells could be detected in the cross-correlogram.

In many cases, we found no neuronal interaction between a cell in layer 5 and a cell in layer 6 , even when their receptive fields overlapped. In fact, only $40 \%$ of all pairs with overlapping receptive fields showed a peak in their cross-correlogram. However, this ratio increased substantially when only cell pairs with matching orientation preference and layer 5 standard complex cells were considered. Among these cases, $87 \%$ pairs with overlapping receptive fields had peaked cross-correlograms (Fig. 6).

With overlapping receptive fields of the layer 5 and layer 6 cells, we always tested whether the layer 5 cell lay within the summation area of the layer 6 cell. For this, we measured the response of the layer 6 cell to a long bar (bar length, 8-12\%), covering the receptive field of the layer 5 cell, and a short bar (bar length, 3-6 $)$, excluding the receptive field of the layer 5 cell. As is characteristic of cells in layer 6 , in all but two cases the response to the long bar was greater than the response to the short bar. Both layer 6 cells with short receptive fields, which had no length summation over the receptive fields of the distant layer 5 cells, also showed no correlated firing with these cells.

Receptive field type. The occurrence of correlated firing between the layer 5 and layer 6 cells also depended on the type of the layer 5 cells, that is, whether the layer 5 cell was a standard or a special complex cell. The two cell pairs in Figure 7 had overlapping receptive fields and similar receptive field properties, with the exception of their length summation characteristics: the layer 5 cell in the upper part of Figure 7 was standard complex, and the layer 5 cell in the lower part was special complex. Predominantly standard complex cells showed correlated firing with the layer 6 cell.

In our sample of 38 peaked cross-correlograms, 32 of the cell pairs included layer 5 standard complex cells and only 4 cell 
Table 4. Relationship of ocular dominance, directionality, end-inhibition, and coherent firing

\begin{tabular}{|c|c|c|}
\hline & \multicolumn{2}{|c|}{ Cross-correlograms } \\
\hline & Peaked & Flat \\
\hline \multicolumn{3}{|c|}{ Difference in ocular dominance classes } \\
\hline $\begin{array}{l}0 \\
1 \\
2 \\
3 \\
4 \\
\text { Total }\end{array}$ & $\begin{array}{c}8(27 \%) \\
12(40 \%) \\
10(33 \%) \\
0(0 \%) \\
0(0 \%) \\
30(100 \%)\end{array}$ & $\begin{array}{c}18(27 \%) \\
25(37 \%) \\
14(21 \%) \\
9(13 \%) \\
1(2 \%) \\
67(100 \%)\end{array}$ \\
\hline \multicolumn{3}{|c|}{ Difference in directionality } \\
\hline $\begin{array}{l}\text { Same } \\
\text { Opposite } \\
\text { Total }\end{array}$ & $\begin{array}{c}12(92 \%) \\
1(8 \%) \\
13(100 \%)\end{array}$ & $\begin{array}{r}4(57 \%) \\
3(43 \%) \\
7(100 \%)\end{array}$ \\
\hline \multicolumn{3}{|c|}{ End-inhibition class of layer 5 cells } \\
\hline $\begin{array}{l}0 \\
1 \\
2 \\
3 \\
\text { Total }\end{array}$ & $\begin{array}{c}15(48 \%) \\
10(32 \%) \\
4(13 \%) \\
2(7 \%) \\
31(100 \%)\end{array}$ & $\begin{array}{c}46(67 \%) \\
6(9 \%) \\
6(9 \%) \\
10(15 \%) \\
68(100 \%)\end{array}$ \\
\hline
\end{tabular}

For ocular dominance, the difference of the ocular dominance classes of the cells in a pair is plotted against the pattern of the cross-correlogram. For directionality, only cells with matching orientation preference (difference, $\left\langle 30^{\circ}\right.$ ) and with both cells directional (class $1-3$ ) were selected.

pairs were found with layer 5 special complex cells; in 2 cell pairs the layer 5 cell could not be classified. These results are summarized in Figure 8.

When performing long recording tracks within layer 5 , we had the impression that standard and special complex cells are not equally distributed within that layer. We therefore measured in all tracks the distance between subsequently recorded cells in layer 5 and noted whether they had equal or different receptive field types. Figure 9 shows that there is a high probability (84\%) for layer 5 cells lying closer than $150 \mu \mathrm{m}$ to be of the same type. However, cells separated by more than $300 \mu \mathrm{m}$ show "equal" or "different" receptive field types at chance level. This finding suggests a clustered distribution of standard and special complex cells in layer 5 .

While the type of the receptive field of layer 5 cells seemed to be critical in producing synchronous firing, this was not the case for layer 6 neurons. We found that both simple and complex cells in layer 6 fired coherently with neurons in layer 5. See Figure 12 for an example of a simple cell in layer 6 that fired in synchrony with a standard complex cell in layer 5 . Our sample of 38 cell pairs with peaked cross-correlograms comprises 12 pairs $(32 \%)$ with layer 6 simple cells. This percentage is almost identical to the frequency of pairs with layer 6 simple cells (33\%) in our whole sample.

Statistical analysis. To test statistically the dependence of correlated firing $(D)$ on the parameters "orientation preference" $(A)$, "receptive field topography" $(B)$, and "receptive field type in layer 5 " $(C)$, we estimated the effect of each parameter using the logistic model described in Materials and Methods. The estimated effects were $A$ upon $D, \beta_{1}=1.31\left(\chi^{2}=20.26, p<\right.$ $0.0001) ; B$ upon $D, \beta_{2}=1.54\left(\chi^{2}=13.05, p<0.0003\right)$; and $C$ upon $D, \beta_{3}=0.97\left(\chi^{2}=7.35, p<0.0067\right)$. Thus, all three effects are significant.

A possible source of error is a dependence between the variables $A, B$, and $C$. To test the hypothesis of dependency, we calculated $\chi^{2}$-values for each pair of variables. The results were as follows: $A$ and $B, \chi^{2}=0.51, p>0.46 ; A$ and $C, \chi^{2}=0.12$, $p>0.72 ; B$ and $C, \chi^{2}=0.08, p>0.77$. None of the $\chi^{2}$-values reached the level of statistical significance, indicating that there is no coupling between the variables. Therefore, the occurrence of correlated firing between cells in layer 5 and layer 6 is in fact dependent upon matching orientation preference, overlapping receptive fields, and the receptive field type of the layer 5 cell.

Variation of the stimulus. The low spontaneous firing rate of cortical cells required recordings to be taken with visual stimuli in order to collect, in a reasonable time, enough spikes to calculate a cross-correlogram. The increase in the firing rate of the cells in response to the stimulus produced broad peaks in the cross-correlograms. This stimulus coordination artifact was eliminated from the cross-correlogram by using the technique described in Materials and Methods.

If the receptive fields lay close enough together, we usually used one bar to stimulate both receptive fields simultaneously. However, if the receptive fields were widely separated or had considerable orientation difference it was necessary to stimulate the two cells with two bars sweeping in synchrony to get sufficient simultaneous responses of both cells. In order to test whether the form of the corrected cross-correlograms depends on the stimulus pattern, we computed in many cases several crosscorrelograms from the same cell pair using different stimulus conditions. In cases such as the one shown in Figure 10 where the orientation preferences were similar and the receptive fields did not overlap but lay close to each other, it was also possible to stimulate the cells using a single moving bar. With a selected speed of the stimulus, we were able to collect enough spikes to compute a cross-correlogram in a manageable time period. Similarly to the cases where we used two bars to stimulate cells with nonoverlapping receptive fields, the cross-correlogram of this cell pair was flat. Moreover, by tilting the bar the responses were less vigorous because the stimulus was suboptimal, but this stimulus condition made the two cells fire at about the same time. Again, the cross-correlogram revealed no sign of correlated firing.

Examples of cell pairs with peaked cross-correlograms are shown in Figures 11 and 12. These pairs consisted of a layer 5 standard complex cell and a layer 6 standard complex cell (Fig. 

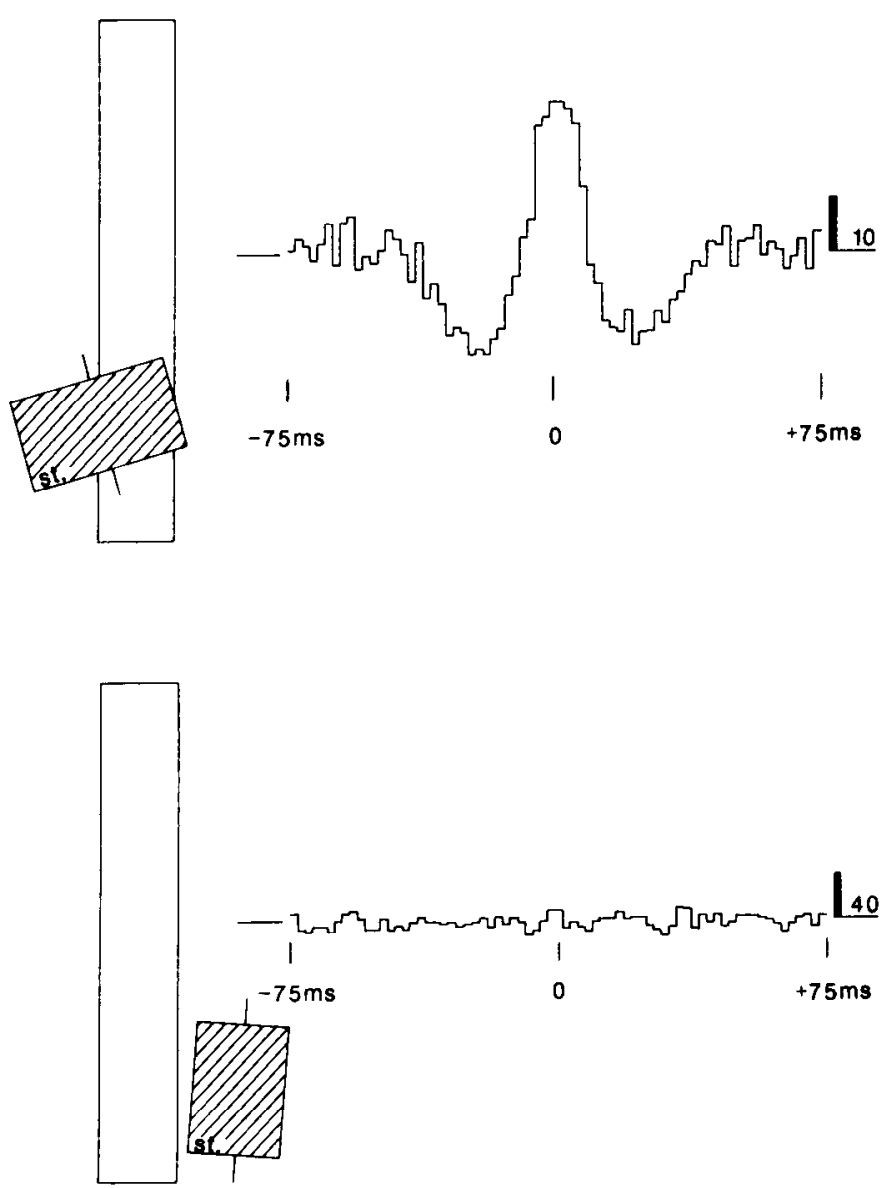

Figure 5. Relationship between receptive field topography and correlated firing (same conventions as in Fig. 3). Top, Shift-corrected crosscorrelogram obtained from standard complex cells in layer 5 and layer 6 separated by $2.5 \mathrm{~mm}$. Both cells could be driven equally well from both eyes and exhibited a strong preference for stimuli moving to the left (directionality class 3 ). The cells had overlapping receptive fields and matching orientation preference (difference, $10^{\circ}$ ). As indicated by the cross-correlogram, they fired in a correlated way. This cross-correlogram had the broadest peak of our total sample (peak width at halfheight, $12 \mathrm{msec}$ ). Size of receptive field of layer 5 cell, $2^{\circ} \times 1^{\circ}$; eccentricity, $7^{\circ}$; one bar stimulus of optimal orientation. Bottom. Standard complex cells in layer 5 and layer 6 (horizontal distance, $2.2 \mathrm{~mm}$ ) with matching orientation preference (difference, $3^{\circ}$ ), same direction preference (directionality class 2), and similar eye preference (layer 5 cell, class 3; layer 6 cell, class 2). As opposed to the top, this cell pair had nonoverlapping receptive fields. The shift-correlated cross-correlogram indicates no significant interaction between the cells. Size of receptive field of layer 5 cell, $1^{\circ} \times 11^{1 / 2^{\circ}}$; eccentricity, $2^{\circ}$; one bar stimulus of optimal orientation.

11) or simple cell (Fig. 12) with like orientation tuning and overlapping receptive fields. We applied optimal and suboptimal stimuli, using either one or two bars. When we stimulated the cells with two bars, they were swept in counterphase over the receptive fields. Under all these different stimulus conditions, the cells fired in synchrony as indicated by the peak in the cross-correlograms.

In all cases where we varied the visual stimulus, we never saw a cross-correlogram with a central peak change into a flat correlogram or vice versa.

Interactions between layer 5 cells. In a few experiments, we also measured neuronal interactions between cells in layer 5 . Peaked cross-correlograms were obtained in 7 out of 20 cell pairs with both cells in layer 5 . Almost all cell pairs with cor-
Matched orientation,

Total sample layer 5 standard complex

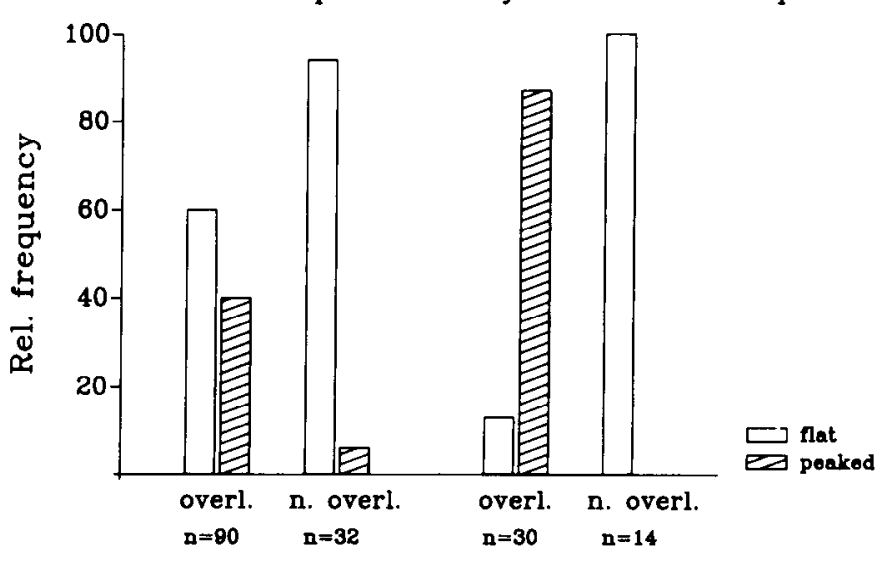

Receptive field topography

Figure 6. Percentage of flat and peaked cross-correlograms between cells in layer 5 and layer 6 . The cell pairs were divided into pairs with overlapping and nonoverlapping receptive fields. Left. All cell pairs. Right, Cell pairs with layer 5 standard complex cells and similar orientation preferences (difference, $<30^{\circ}$ ).

related firing had similar orientation preferences ( 6 out of 7$)$, and 4 cell pairs with peaked cross-correlograms had nonoverlapping receptive fields. In two cases we obtained flat crosscorrelograms from distant cells in layer 5 with nonoverlapping receptive fields and similar orientation preferences. We then advanced one electrode vertically into layer 6 , as judged by subsequent histological reconstruction of the electrode track, and obtained a peaked cross-correlogram.

\section{Discussion}

The present cross-correlation analysis reveals a high degree of specificity in the interactions between cells in layer 5 and layer 6. Correlated firing was only observed if the layer 5 cell lay within the summation area of the layer 6 cell and if the two cells had similar orientation preferences. Both cell classes encountered in layer 6 , simple cells and standard complex cells, showed correlated firing with layer 5 cells. However, only a subset of the cells in layer 5 participated in the correlated firing with the cells in layer 6: most peaked cross-correlograms were obtained with layer 5 standard complex cells, but rarely with layer 5 special complex cells.

\section{Functional connections revealed by cross-correlation analysis}

All cross-correlograms in our study that showed any sign of interactions between the two recorded cells had positive peaks straddling the zero bin. Such cross-correlograms are interpreted to reflect common synaptic input from other neurons (Perkel et al., 1967; Moore et al., 1970). Generally, this is the prevalent pattern of interaction found between cortical cells (Dickson and Gerstein, 1974; Toyama et al., 1981a,b; Michalski et al., 1983; Ts'o et al., 1986). Direct monosynaptic connections produce asymmetric peaks (excitation) or troughs (inhibition) in the crosscorrelograms. These interactions are much less frequently observed in the cortex than shared input, and they are usually only seen if the cells lie very close to each other (Toyama et al., 1981a,b; Michalski et al., 1983). One reason why inhibitory 


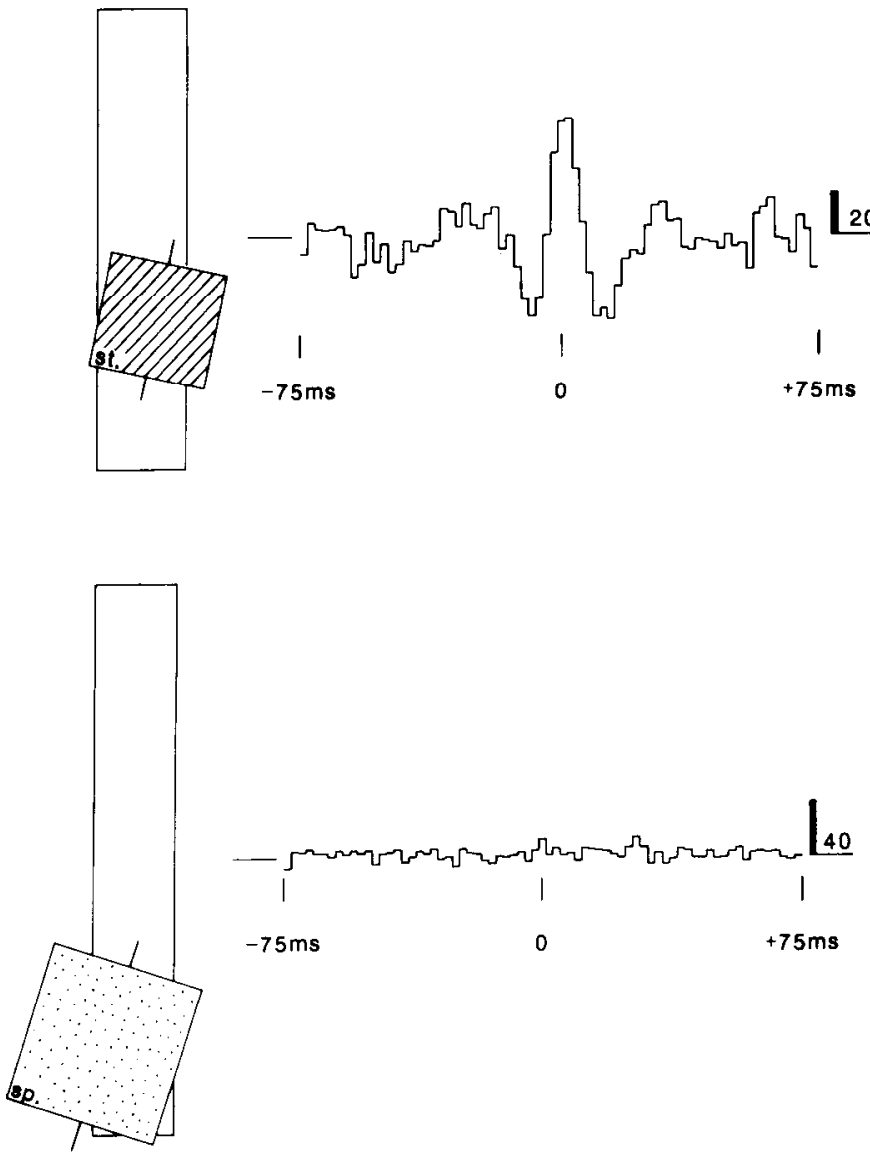

Figure 7. Dependency of coherent firing on the receptive field type of the layer 5 cell (same conventions as in Fig. 3). Top. Two standard complex cells, one in layer 5 and one in layer 6 (distance, $1.5 \mathrm{~mm}$ ), with overlapping receptive fields. Both cells preferred the contralateral eye (ocular dominance class 6) and the same orientation of the stimulus. The cells and in synchrony (peak width at half-height, $7 \mathrm{msec}$ ). Size of

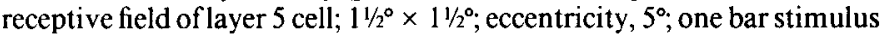
of optimal orientation. Bottom, Special complex, $(s p$.) cell in layer 5 and standard complex ccll in laycr 6 (distance, $2.7 \mathrm{~mm}$ ) with overlapping receptive fields, matching orientation preference, and similar ocular dominance (layer 5 cell, class 4 ; layer 6 cell, class 5 ). The shift-corrected cross-correlogram indicates no coherent firing between the two cells. Size of receptive fields: layer 5 cell, $2^{\circ} \times 2^{\circ}$; eccentricity, $4^{\circ}$; two bar stimulus.

interactions are rarely visible with cross-correlation analysis could be due to the methods employed. It has been theoretically shown that this technique is incapable of detecting inhibition if the average firing rates of the cells under investigation are low, as it is often the case in the cortex (Aertsen and Gerstein, 1985; Palm et al., 1988).

Recently, oscillatory patterns in auto- and cross-correlograms of cortical neurons were reported (Gray and Singer, 1987; Eckhorn et al., 1988; Gray et al., 1989). According to these studies, oscillations at distant locations in the cortex are synchronized in a stimulus-specific manner. In the present study, we also observed cells that showed oscillatory responses as indicated by the auto- and cross-correlograms (e.g., Fig. 3), and in some instances we noted a change of the oscillatory side peaks with variation of the stimulus. However, in all cases tested the central peak was unaffected by the nature of the stimulus used. For example, the cell pair in Figure 11 showed a central peak with oscillatory side peaks in one half of the cross-correlogram when stimulated with a single bar. This oscillation was suppressed

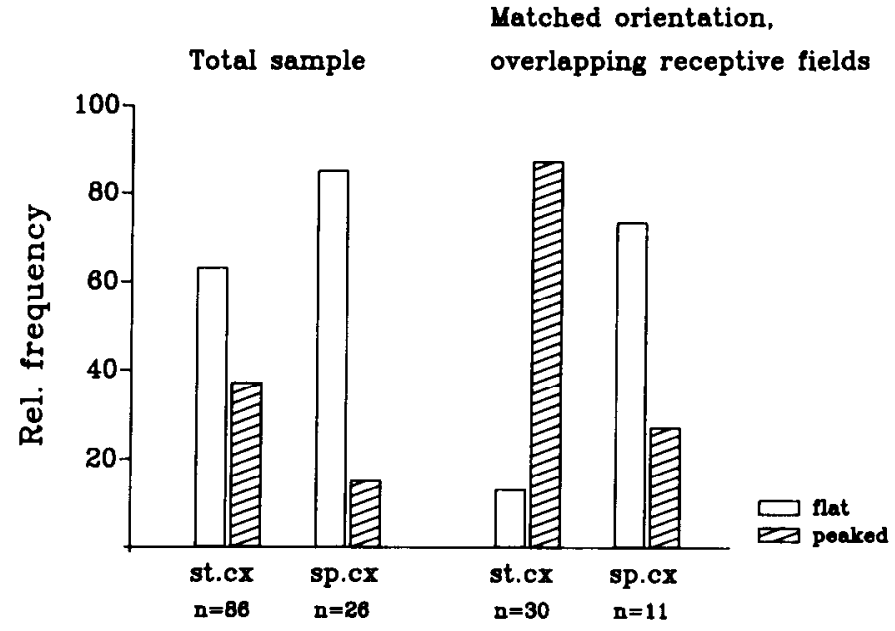

Receptive field type of layer 5 cell

Figure 8. Percentage of flat and peaked cross-correlograms between cells in layer 5 and layer 6 . The cell pairs were divided into pairs with layer 5 standard complex (st.cx) cells and layer 5 special complex (sp.cx) cells. Left, All cell pairs. Right, Cell pairs with similar orientation preferences (difference, $\left\langle 30^{\circ}\right.$ ) and overlapping receptive fields.

when the cells were stimulated with two bars, but the central peak in the cross-correlogram was not influenced by this change of stimulus condition. This cell pair also demonstrates that oscillatory components may show up on only one side in the cross-correlogram, indicating that only one of the two cells fired in an oscillating manner. If the only form of neuronal interaction was a stimulus-dependent synchronization of oscillatory responses, then the resulting cross-correlograms should show oscillatory components on either side of the zero bin. In our study, the central peaks in the cross-correlograms, in contrast to the oscillatory components, persist with variation of the stimulus. Our interpretation of this finding is that there are stable horizontal connections upon which oscillating responses of one or both of the cells may be superimposed.

\section{Distance between cells in layer 5}
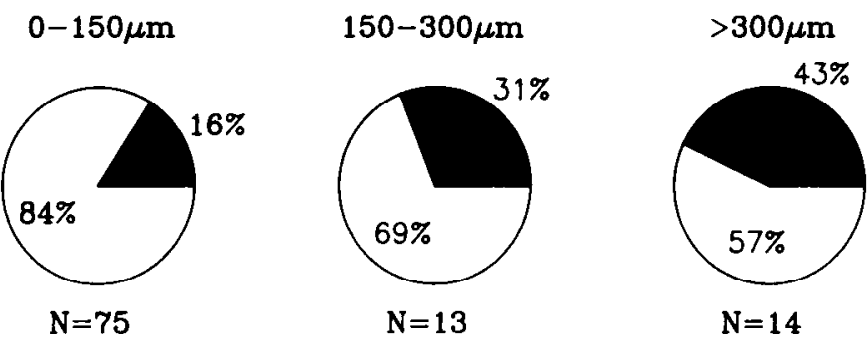

Receptive field type: equal(st.-st. or sp.-sp.)

$$
\text { different(st. -sp.) }
$$

Figure 9. Clustering of standard and special complex cells in layer 5. The plot shows the probability of two consecutively recorded cells hav. ing equal or different receptive field types for various distances between the cells. Abbreviations: st., standard complex cell; $s p$., special complex cell. 


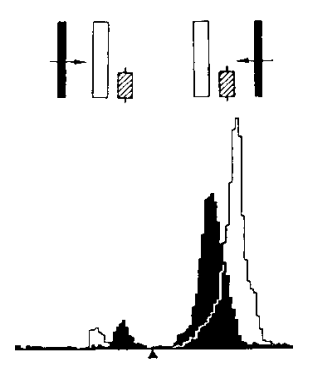

$\left.\left.\right|_{-75 \mathrm{~ms}} ^{4}\right|_{0} ^{140}$

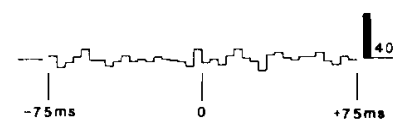

Figure 10. Variation of the stimulus. Standard complex cells in layer 5 and layer 6 with matching receptive field properties, but nonoverlapping receptive fields (layer 5 cell, cross-hatched box; layer 6 cell, open box; stimulating bar, solid rectangle). In this case, the receptive fields were close enough so that the cells' response to a single bar with a selected speed overlapped in time; see poststimulus time histograms in the middle (layer 5 cell; solid histogram, layer 6 cell, open histogram; triangles indicate reversal of the stimulus direction; duration for movement in both directions, $3 \mathrm{sec}$ ). Left. Stimulation with an optimally oriented bar. Right, Stimulation with a single bar rotated by $20^{\circ}$ off the optimum to increase the temporal overlap of the cells' responses. In both cases, a flat cross-correlogram was obtained (bottom).

With common input interactions, the question arises of where the common driver of the two cells is located. The stimulus as source of synchronous input to the cells was excluded by subtracting the stimulus coordination artifact from the raw crosscorrelogram (see Materials and Methods). There is evidence that retinal ganglion cells show correlated firing due to common input (Mastronarde, 1983a,b). If these correlated inputs are transmitted to the cortex, one should find rather broad and weak
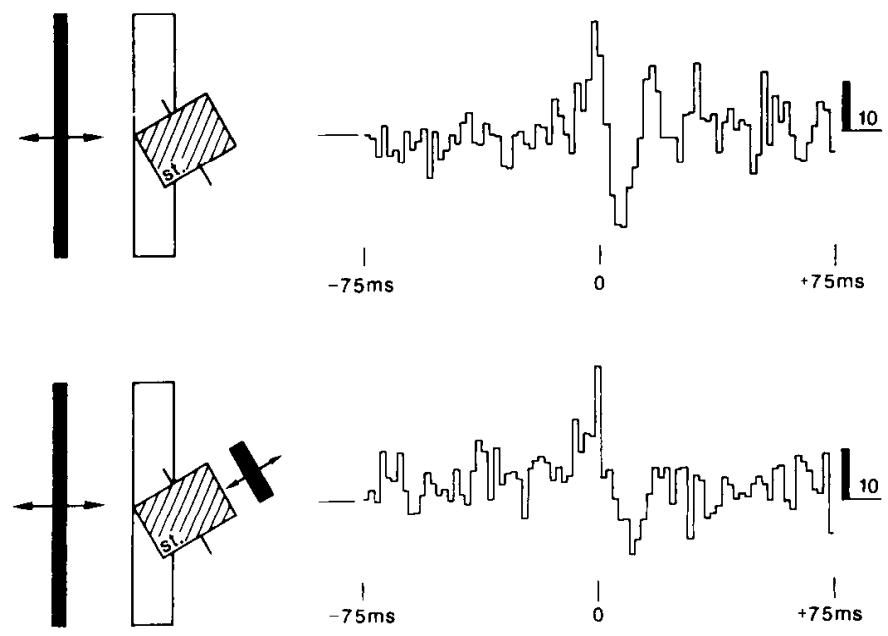

Figure 11. Variation of the stimulus. Cell pair with similar receptive field properties (difference in orientation preference, $27^{\circ}$ ) and overlapping receptive fields. Top, Stimulation with a single bar; bottom, stimulation with two light bars swept in counterphase across the receptive fields. The central peaks in the cross-correlograms indicate correlated firing of the cells for both stimulus conditions. Note additional side peaks in the right half of the cross-correlogram for the stimulation with a single bar. These side peaks disappeared when the cells were stimulated with two bars, but the central peak remained unaffected.
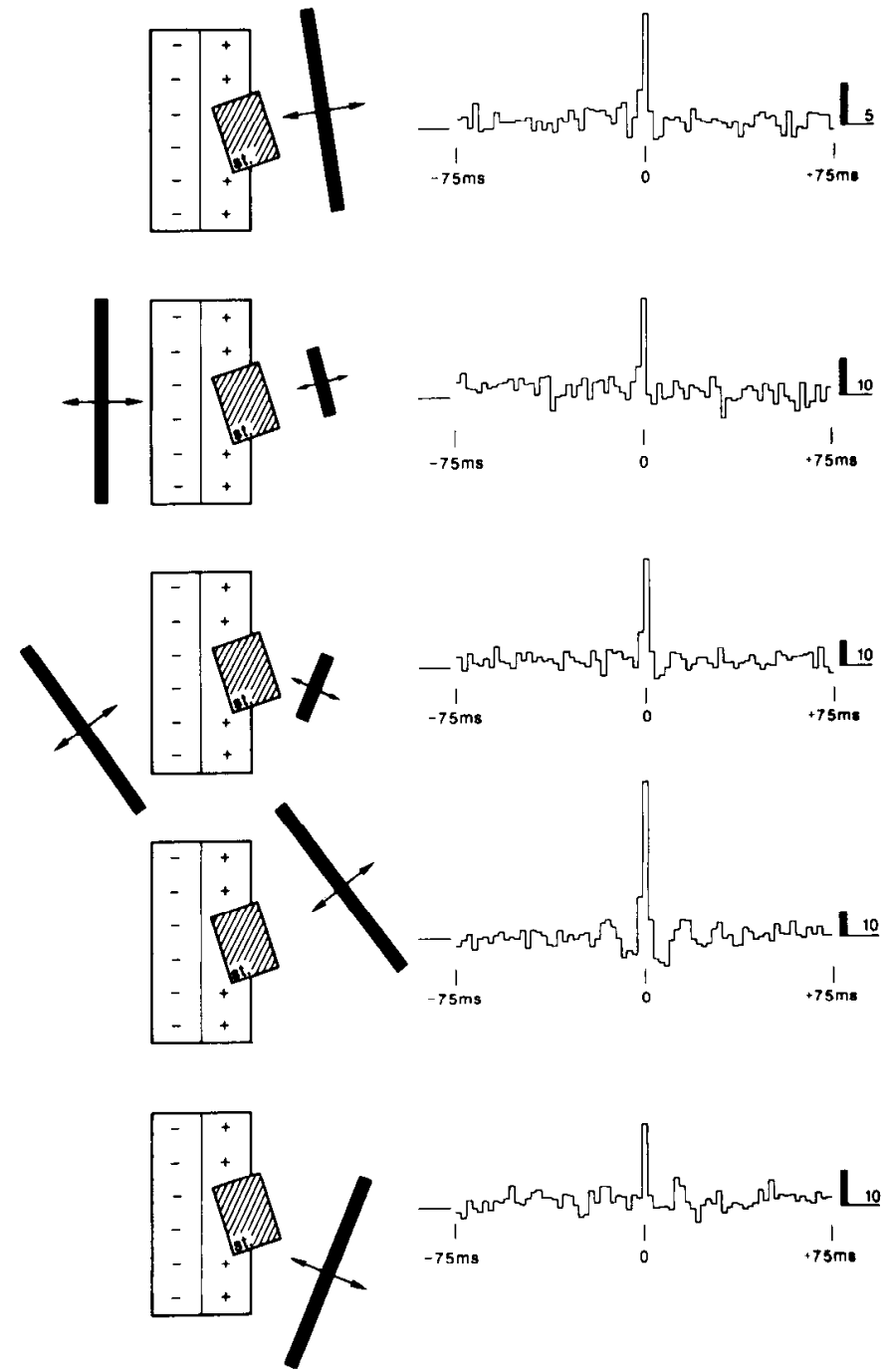

Figure 12. Variation of the stimulus: layer 5 standard complex cell and layer 6 simple cell with overlapping receptive fields and slightly different orientation preference $\left(16^{\circ}\right)$. Five different stimulus conditions were applied. From top to bottom: single bar oriented between the preferred orientations of the two cells; two bars (moving in counterphase) with optimal orientation for each cell; two bars (moving in counterphase) with suboptimal orientations for each cell (deviation, $30^{\circ}$ ); single suboptimal bar (deviation, $30^{\circ}$ ); single suboptimal bar (deviation, $30^{\circ}$, opposite direction). Under all these stimulus conditions, the central peak in the cross-correlogram remained stable.

cross-correlogram peaks in the cortex, since they have to pass at least two synapses. Cross-correlograms with broad peaks, 30$100 \mathrm{msec}$ wide, have been observed among some cells in monkey visual cortex and have been attributed to intraretinal interactions (Krüger and Aiple, 1988). In our sample, we never encountered peaks in that range. The observed shared input therefore arises either from other cortical cells or from the geniculate input. The horizontal spread of geniculate afferents in the cortex is quite restricted; for example, the largest arbor recovered by Humphrey et al. (1985) had a surface area of 1.8 $\mathrm{mm}^{2}$, and its maximum extent was less than $2 \mathrm{~mm}$. From this, one would expect that correlated firing of cells separated by more than $2 \mathrm{~mm}$ is due to cortical connections. Moreover, we found that correlated firing was dependent on the orientation preference of the cells, whereas cells in the geniculate nucleus have center-surround receptive fields. It has been reported that a 
portion of geniculate cells displays a bias for a particular orientation (Levick and Thibos, 1982; Shou and Leventhal, 1989). However, individual geniculate arbors innervate a full ocular dominance column, making it very unlikely that they contact cells of a single orientation (LeVay and Gilbert, 1976; Ferster and LeVay, 1978; Blasdel and Lund, 1983; Humphrey et al., 1985). Thus, the correlated firing observed in the present study is of cortical origin, since it is related to the columnar architecture of the cortex.

Long-range interactions with clustered terminals are present within area 17 and between different visual cortical areas (Gilbert and Kelly, 1975; Gilbert and Wiesel, 1979, 1989; Bullier et al., 1984). Very little is known about the termination of the interareal projections in cat area 17 , so we cannot rule out the possibility that extrastriate input contributes to the coherent firing between layer 5 and layer 6 cells. However, several anatomical studies based on investigations of neurons filled in vivo with HRP (Gilbert and Wiesel, 1983; Martin and Whitteridge, 1984) and on intracellular injections in vitro with the fluorescent dye Lucifer yellow (Hübener et al., 1990) demonstrated the presence of many pyramidal cells in layer 5 with axonal arbors extending over several millimeters into layer 6 . Furthermore, as discussed in more detail in the last section, physiological experiments demonstrated that the response of layer 6 cells is dependent upon neuronal activity in layer 5 (Bolz and Gilbert, 1989). Taken together, these results suggest that the intrinsic interlaminar projection plays an important role in the correlated firing of cells in layer 5 and layer 6 .

Cells in layer 5 , in addition to the long-ranging projections in layer 6 , also have many local axon collaterals near their own dendritic tree (Gilbert and Wiesel, 1979, 1983; Martin and Whitteridge, 1984; Gabott et al., 1987; Hübener et al., 1990). This allows layer 5 cells to make contact with many other cells in their vicinity. Indeed, electrical stimulation experiments demonstrated that neighboring cells in layer 5 are synaptically connected (Thalluri and Henry, 1989). One might expect from such a highly interconnected system that the contribution of an individual cell to the response of their postsynaptic neurons is relatively weak. Thus, even if a cell recorded in layer 5 directly contacts the cell recorded in layer 6 , this monosynaptic connection is occluded in the cross-correlogram by the vast common input from many other layer 5 cells. This explains the prevalence of common input peaks observed in the present study. However, we found a close relationship between the occurrence of a peak in the cross-correlogram and the functional properties of the two individual cells recorded in layers 5 and 6. Why does the correlated firing between two cells, which reflect the influence of many other neurons, depend on the functional properties of just these two single neurons? If the common input did indeed arise from highly interconnected adjacent cells in layer 5 , then these cells would have similar orientation preference and similar receptive field topography (Hubel and Wiesel, 1977), as well as similar length summation characteristics (present study). Thus, it would not be unexpected to find relationships between these properties and the shared input correlation as reported in this study.

\section{Orientation specificity and receptive field topography}

We observed correlated firing between layer 5 and layer 6 cells only if the cells had similar orientation specificity. This confirmed the idea that the clustered projections of the layer 5 cells are related to columns with similar orientation preference
(Mitchison and Crick, 1982; Gilbert and Wiesel, 1983). It is also in accordance with an earlier cross-correlation study showing that horizontal projections in the superficial layers connect cells with the same orientation specificity (Ts'o et al., 1986). Synchronized oscillatory interactions between horizontally displaced cells were predominantly seen when the orientation preferences of the cells matched (Eckhorn et al., 1988; Gray et al., 1989). Gilbert and Wiesel (1989) combined very small tracer injections in the superficial layers of area 17 with the deoxyglucose method to label the orientation columns. They found that only cells with similar orientation preference were interconnected. Taken together, these studies suggest that the patchy horizontal connections in area 17 are related to the tendency of cells to communicate with other cells having the same orientation preference.

Quite different observations have been made in area 18 by Matsubara and colleagues (Matsubara et al., 1985, 1987). Using electrophysiological recordings, these authors obtained an orientation map and then injected small amounts of retrograde tracers at the center of the mapped region. They reported that horizontal connections in area 18 tended to interconnect columns with orthogonal orientation preference, and therefore suggested that long-range connections generate cross-orientation inhibition. It is possible that there are differences in the intrinsic connections between areas 17 and 18 . However, these experiments have been criticized for methodological reasons because it is difficult to compare maps obtained in the living animals with projection patterns that are only seen after fixation and histological processing (Gilbert and Wiesel, 1989). Since we used a cross-correlation technique, which as mentioned above is rather insensitive to detect inhibitory interactions, we cannot exclude the existence of long-range inhibitory connections in area 17. However, several anatomical studies showed that cells in layers $2 / 3$ and 5 with long axon collaterals established type I (asymmetric) contacts, which are thought to be excitatory (McGuire et al., 1985; Kisvárday et al., 1986; Gabbott et al., 1987; LeVay, 1988). The large majority of these synaptic contacts were made on other excitatory cells, suggesting that horizontal connections produce primarily excitatory influences.

Clustered intrinsic connections havc also bcen scen after relatively large extracellular HRP injections, including columns of all orientation preferences (Rockland and Lund, 1982; Luhmann et al., 1986). If all cells with similar orientation preferences were interconnected, this would lead to a rather uniform horizontal pattern of HRP label. To account for the patchiness, Mitchison and Crick (1982) suggested that connections of cells with like orientations exist only along a particular direction of the cortex. Since the striate cortex is visuotopically organized, one might then expect to find a relationship between the system of horizontal connections and the receptive field topography. In the present study, we provide evidence for such a relationship in the interactions between cells in layer 5 and layer 6 . Cells with matching orientation preference were only seen to fire synchronously if they had overlapping receptive fields. Thus, cells with collinearly aligned receptive fields are interconnected, but cells with parallel receptive fields are not. An anisotropy is also apparent in the axonal arbors of individual cells. The axonal projections of layer 5 cells are highly asymmetric: they extend along one cortical direction for greater distances than along the respective orthogonal direction (Gilbert and Wiesel, 1983; Martin and Whitteridge, 1984; Gabbott et al., 1987). We propose that the dependency of coherent firing on receptive field positions 
found in this study is the physiological counterpart of the anisotropic projection of the layer 5 cells into layer 6 .

An anisotropic labeling has also been observed in the study of Gilbert and Wiesel (1989) already mentioned. By combining retrograde labeling and the deoxyglucose method, they found connections only among cells with similar orientation preference. Some isoorientation columns, however, even close to the injection site, were devoid of retrogradely labeled cells. Ts'o et al. (1986) found quite a number of cell pairs in the superficial layers with like orientation that did not show correlated firing, but they did not report about the receptive field positions of these cell pairs. Nelson and Frost (1985) reported facilitatory effects from beyond the classic receptive field in cells of the superficial layers. This facilitation was mediated by cells with matching orientation preference and was suppressed if parts of the visual field along the orientation axis were obscured by a mask. Thus, connections among cells with collinearly aligned receptive fields are perhaps the predominant pattern in other cortical layers as well.

\section{Circuitry of layer 5 cells}

There are two populations of neurons in layer 5, standard complex cells and special complex cells. Studies by Malpeli and colleagues provided evidence that the two types of complex cells receive input from different intracortical pathways. They found that inactivation of the A-layers in the lateral geniculate blocked the activity of standard complex cells in layer 5, whereas the special complex cells were not affected (Weyand et al., 1986). Electrical stimulation experiments have shown that cells in layer 5 do not receive monosynaptic input from the lateral geniculate nucleus (Ferster and Lindström, 1983; but see Martin and Whitteridge, 1984). However, since the responses of cells in layer 4 and layer 6 also depended on activity of the A-layers (Malpeli, 1983; Malpeli et al., 1986), Weyand et al. (1986) proposed that standard complex cells in layer 5 are driven by input from layer 5 and/or layer 6 . On the other hand, by destruction of the superficial layers, special complex but not standard complex cells in layer 5 were silenced (Schwark et al., 1986). This suggests that cells in the supragranular layers provide the major input for special complex cells.

Our results indicate that standard and special complex cells of layer 5 also differ in their intrinsic cortical connections. Standard complex cells, but very few special complex cells, showed correlated firing with cells in layer 6 . The cortical target cells of special complex cells are not known; perhaps these cells project back to the superficial layers. Thus, the two types of complex cells in layer 5 participate in segregated cortical circuits and might therefore play very different roles in intracortical information processing.

\section{Functional implications}

It has been suggested that a possible functional role of the longranging horizontal connections might be the construction of long receptive fields (Gilbert and Wiesel, 1979; Mitchison and Crick, 1982; Bolz and Gilbert, 1989). Experimental support for this proposal came from experiments where a defined region in the cortex was reversibly inactivated by injection of the inhibitory transmitter GABA. When layer 5 was locally blocked, cells in layer 6 were no longer responsive over the portion of their receptive field corresponding to the inactivated region of layer 5 (Bolz and Gilbert, 1989). Such an effect was seen with layer 6 cells separated horizontally for up to $3 \mathrm{~mm}$ from the inacti- vated area in layer 5 . This demonstrates that neurons in layer 6 receive input from layer 5 cells that are distributed over a wide range in layer 5 . If the long receptive fields of layer 6 cells are generated by convergence of input from layer 5 , one would then expect a rather specific wiring: cells in layer 6 should receive input from cells in layer 5 with matching orientation specificity and with receptive field positions aligned along the orientation axis of the layer 6 cells. The present cross-correlation analysis indicates that such a scheme is realized by interlaminar connections from layer 5 to layer 6 .

Another cortical pathway that might account for the long receptive fields of layer 6 cells and the correlated firing between cells in layers 5 and 6 observed in the present study could be local projections from layer 5 to layer 6 followed by connections intrinsic to layer 6 . Since the spread of axon collaterals of layer 6 cells is rather limited (Katz, 1987), this model would require a cascade of connections within layer 6 . But this seems rather unlikely, since local inactivation of layer 6 , rather than layer 5 , has no effect on distant cells in layer 6 (Bolz and Gilbert, 1989). Alternatively, there could be long-distance connections within layer 5 coupled with local projections from layer 5 to layer 6 . In fact, one of the intracellularly stained layer 5 cells of Martin and Whitteridge (1984) had long-ranging axon collaterals straddling the border between layer 5 and layer 6 . Consistent with this, we obtained in a few cases peaked cross-correlograms from widely separated layer 5 cells with nonoverlapping receptive fields. However, local projections betwecn layers 5 and 6 cannot account for the length summation properties of layer 6 cells, because layer 5 cells have much shorter receptive fields than layer 6 cells. Moreover, in some cases we observed no coherent firing between distant layer 5 cells, but a peaked cross-correlogram was obtained after one of the electrodes had been advanced within the same vertical column into layer 6 . Thus, it seems most plausible that the correlated firing between distant cells in layers 5 and 6 is largely due to the long-range direct projection from layer 5 to layer 6 .

We found that both simple and complex cells in layer 6 fire in synchrony with coaxially aligned cells in layer 5 . This is in accordance with inactivation experiments that showed that length summation of both cell classes in layer 6 depends on input from layer 5 (Bolz and Gilbert, 1989). Since almost all cells in layer 5 are complex, simple cells in layer 6 may retain their simple receptive field structure by combining the input from laycr 5 with input from the geniculate, perhaps by an AND-gating mechanism. Such a neuronal mechanism has also been suggested to underlie the response properties of bimodal cells in the prestriate cortex (Benevento et al., 1977).

With the inactivation technique used by Bolz and Gilbert (1989), it is not possible to characterize the cells in layer 5 that provide input to layer 6 . The present study addressed this weakness with cross-correlation analysis. We found peaked crosscorrelograms primarily with layer 5 standard complex cells and only rarely with special complex cells. This suggests that the cells in layer 6 receive their input from a distinct subset of layer 5 cells, the standard complex cells. Complementary support for our proposal that standard complex cells in layer 5 construct the long receptive fields in layer 6 comes from the study by Schwark et al. (1986). As mentioned in the previous section, these authors found that when the superficial layers are destroyed by cryogenic lesions, special complex cells are silenced, whereas standard complex cells can still be recorded in layer 5 . The length summation of the layer 6 cells was unaffected by the 
removal of supragranular layer activity. These experiments indicate that the response properties of layer 6 cells do not depend on activity of layer 5 special complex cells, which is consistent with our finding that cells in layer 6 receive their input from standard complex cells in layer 5 .

The length summation properties of layer 5 standard complex cells match very well with the length summation characteristics of the layer 6 cells, which also increase their response gradually as the stimulating bar is lengthened. However, the contribution from the peripheral parts in the receptive field of layer 6 cells is only seen when the center of the receptive field is stimulated at the same time. Thus, a long bar with a gap in the central region elicits no response in layer 6 cells. This is comparable to other physiological properties thought to be related to longranging connections. Stimulating the surrounding parts of receptive fields alone elicits no response from the cells, but this may have a profound influence on responses from stimuli presented within the classical receptive field (Zeki, 1983; Allman et al., 1985). Thus, the influence of horizontal projection systems seems to be modulatory in nature and might require similar mechanisms of integration.

\section{References}

Aertsen AMHJ, Gerstein GL (1985) Evaluation of neuronal connectivity: sensitivity of cross-correlation. Brain Res 340:341-354.

Aertsen AMHJ, Gerstein GL, Habib MK, Palm G (1989) Dynamics of neuronal firing correlation: modulation of "effective connectivity." J Neurophysiol 61:900-917.

Allman JM, Miezin FM, McGuinness E (1985) Direction- and velocity-specific responses from beyond the classical receptive field in the middle temporal visual area (MT). Perception 14:105-126.

Barlow HB, Blakemore C, Pettigrew JD (1967) The neural mechanism of binocular depth discrimination. J Physiol (Lond) 193:327-342.

Benevento A, Fallon J, Davis BJ, Rezak M (1977) Auditory-visual interaction in single cells in the cortex of the superior temporal sulcus and the orbital frontal cortex of the macaque monkey. Exp Neurol $57: 849-872$.

Blasdel GG, Lund SL (1983) Termination of afferent axons in macaque striate cortex. J Neurosci 3:1389-1413.

Bolz J, Gilbert CD (1986) Generation of end-inhibition in the visual cortex via interlaminar connections. Nature 321:362-365.

Bolz J, Gilbert CD (1989) The role of horizontal connections in generating long receptive fields in the cat visual cortex. Eur J Neurosci $1: 263-268$.

Bolz J, Gilbert CD, Wiesel TN (1989) Pharmacological analysis of cortical circuitry. Trends Neurosci 12:292-296.

Bullier J, Kennedy H, Salinger W (1984) Branching and laminar origin of projections between visual cortical areas in the cat. J Comp Neurol 228:329-341.

Cox DR (1970) The analysis of binary data. London: Methuen.

Dickson JW, Gerstein GL (1974) Interactions between neurons in auditory cortex of the cat. $J$ Neurophysiol 37:1239-1261.

Eckhorn R, Bauer R, Jordan W, Brosch M, Kurse W, Munk M, Reitboeck HJ (1988) Coherent oscillations: a mechanism of feature linking in the visual cortex? Multiple electrode and correlation analyses in the cat. Biol Cybern 60:121-130.

Eysel UT, Wörgötter F, Pape H-C (1987) Local cortical lesions abolish lateral inhibition at direction selective cells in cat visual cortex. Exp Brain Res 68:606-612.

Ferster D, LeVay S (1978) The axonal arborizations of lateral geniculate neurons in the striate cortex of the cat. J Comp Neurol 182: 923-943.

Ferster D, Lindström S (1985) Synaptic excitation of neurones in area 17 of the cat by intracortical axon collaterals of cortico-geniculate cells. J Physiol (Lond) 367:233-252.

Gabbott PLA, Martin KAC, Whitteridge D (1987) Connections between pyramidal neurons in layer 5 of cat visual cortex (area 17). J Comp Neurol 259:364-381.

Gerstein GL, Pcrkcl DH (1972) Mutual temporal rclationships among neuronal spike trains. Biophys J 12:453-473.

Gilbert CD (1977) Laminar differences in receptive field properties in cat primary visual cortex. J Physiol (Lond) 268:391-421.

Gilbert CD, Kelly JP (1975) The projections of cells in different layers of the cat's visual cortex. J Comp Neurol 163:81-105.

Gilbert CD, Wiesel TN (1979) Morphology and intracortical projections of functionally characterized neurones in the cat visual cortex. Nature 280:120-125.

Gilbert CD, Wiescl TN (1983) Clustered intrinsic connections in cat visual cortex. J Neurosci 3:1116-1133.

Gilbert CD, Wiesel TN (1989) Columnar specificity of intrinsic horizontal and corticocortical connections in cat visual cortex. J Neurosci 9:2432-2442.

Gray CM, Singer W (1987) Stimulus-specific neuronal oscillations in the cat visual cortex: a cortical functional unit. Soc Neurosci Abstr 13:1449.

Gray CM, König P, Engel AK, Singer W (1989) Oscillatory responses in cat visual cortex exhibit inter-columnar synchronization which reflects global stimulus properties. Nature 338:334-337.

Harvey AR (1980) A physiological analysis of subcortical and commissural projections of areas 17 and 18 of the cat. J Physiol (Lond) 302:507-534

Henry GH, Harvey AR, Lund JS (1979) The afferent connections and laminar distribution of cells in the cat striate cortex. J Comp Neurol 187:725-744.

Hubel DH (1957) Tungsten microelectrode for recording from single units. Science 125:549-550.

Hubel DH, Wiesel TN (1962) Receptive fields, binocular interaction and functional architecture in the cat's visual cortex. J Physiol (Lond) 160:106-154.

Hubel DH, Wiesel TN (1977) Functional architecture of the visual cortex. Proc R Soc Lond [Biol] 198:1-59.

Hübener M, Schwarz C, Bolz J (1990) Morphological types of projection neurons in layer 5 of cat visual cortex. J Comp Neurol 301: 655-674.

Humphrey AL, Sur M, Uhlrich DJ, Sherman SM (1985) Termination patterns of individual $\mathrm{X}$ - and $\mathrm{Y}$-cell axons in the visual cortex of the cat: projections to area 18 , to the $17 / 18$ border region, and to both areas 17 and 18. J Comp Neurol 233:190-212.

Katz LCJ (1987) Local circuity of identified projection neurons in cat visual cortex brain slices. J Neurosci 7:1223-1249.

Kisvárday ZF, Martin KAC, Freund TF, Maglóczky Z, Whitteridge D, Somogyi P (1986) Synaptic targets of HRP-filled layer III pyramidal cells in the cat striate cortex. Brain Res 64:541-552.

Krüger J, Aiple F (1988) Multimicroelectrode investigation of monkey striate cortex: spike train correlations in the infragranular layers. J Neurophysiol 60:798-828.

LeVay $\mathrm{S}$ (1988) Patchy intrinsic projection in visual cortex, area 18 , of the cat: morphological and immunocytochemical evidence for an excitatory function. J Comp Neurol 269:265-274.

LeVay S, Gilbert CD (1976) Laminar patterns of geniculocortical projection in the cat. Brain Res 113:1-19.

Leventhal AG, Hirsch HVB (1978) Receptive field properties of neurons in different laminae of visual cortex of the cat. J Neurophysiol 41:948-962.

Levick WR, Thibos LN (1982) Analysis of orientation bias in cat retina. J Physiol (Lond) 329:243-261.

Lorente de Nó R (1933) Studies on the structure of the cerebral cortex. J Psychol Neurol 45:382-438.

Luhmann HJ, Martinez Millán L, Singer W (1986) Development of horizontal intrinsic connections in cat striate cortex. Exp Brain Res 63:443-448.

Lund JS, Henry GH, Macqueen CL, Harvey AR (1979) Anatomical organization of the primary visual cortex (area 17) of the cat. A comparison with area 17 of the macaque monkey. J Comp Neurol 184:599-618.

Malpeli JG (1983) Activity of cells in area 17 of the cat in absence of input from layer A of lateral geniculate nucleus. J Neurophysiol 49: 595-610

Malpeli JG, Lee C, Schwark HD, Weyand TG (1986) Cat area 17. I. Pattern of thalamic control of cortical layers. J Neurophysiol 56:10621073.

Martin KAC, Whitteridge D (1984) Form, function and intracortical projections of spiny neurons in the striate cortex of the cat. J Physiol (Lond) 353:463-504.

Mastronarde DN (1983a) Correlated firing of cat retinal ganglion cells. I. Spontaneously active inputs to X-and Y-cells. J Neurophysiol 49: 303-324 
Mastronarde DN (1983b) Correlated firing of cat retinal ganglion cells. II. Responses of $\mathrm{X}$ - and $\mathrm{Y}$-cclls to single quantal events. J Neurophysiol 49:325-349.

Matsubara JA, Cynader M, Swindale NV, Stryker MP (1985) Intrinsic projections within visual cortex: evidence for orientation specific local connections. Proc Natl Acad Sci USA 82:935-939.

Matsubara JA, Cynader MS, Swindale NV (1987) Anatomical properties and physiological correlates of the intrinsic connections in cat area 18. J Neurosci 7:1428-1446.

McGuire BA, Gilbert CD, Wiesel T (1985) Ultrastructural characterization of long-range clustered horizontal connections in monkey striate cortex. Soc Neurosci Abstr 11:17.

Michalski A, Gerstein GL, Czarkowska J, Tarnecki R (1983) Interactions between cat striate cortex neurons. Exp Brain Res 51:97-107.

Mitchison G, Crick F (1982) Long axons within the striate cortex: their distribution, orientation, and patterns of conncction. Proc Natl Acad Sci USA 79:3661-3665.

Moore GP, Perkel DH, Segundo JP (1970) Statistical signs of synaptic interaction in neurons. Biophys J 10:876-900.

Nelson JI, Frost BJ (1985) Intracortical facilitation among co-oriented, co-axially aligned simple cells in cat striate cortex. Exp Brain Res 61: 54-61.

Otsuka R, Hassler R (1962) Über Aufbau und Gliederung der corticalen Sehsphäre bei der Katze. Arch Psychiatr Nervenkr 203:212-234.

Palm G, Aertsen AMHJ, Gerstein GL (1988) On the significance of correlations among neuronal spike trains. Biol Cybern 59:1-11.

Palmer LA, Rosenquist AC (1974) Visual receptive fields of single striate cortical units projecting to the superior colliculus in the cat. Brain Res 67:27-42.

Perkel DH, Gerstein GL, Moore GP (1967) Neuronal spike trains and stochastic point processes. II. Simultaneous spike trains. Biophys J $7: 419-440$.

Ramón y Cajal S (1921) Textura de la corteza visual del gato [transl]. In: Cajal on the cerebral cortex. Arch Neurobiol 2:338-362.

Ribak CE (1978) Aspinous and sparsely-spinous stellate neurons in the visual cortex of rats contain glutamic acid decarobxylase. J Neurocytol 7:461-478.

Rockland KS, Lund JS (1982) Widespread periodic intrinsic connections in the tree shrew visual cortex. Science 215:1532-1534.

Schwark HD, Malpeli JG, Weyand TG, Lee C (1986) Cat area 17. II. Response properties of infragranular layer neurons in the absence of supragranular layer activity. J Neurophysiol 56:1074-1087.

Shou T, Leventhal AD (1989) Urganized arrangement of orientationsensitive relay cells in the cat's dorsal lateral geniculate nucleus. J Neurosci 9:4287-4302.

Sillito AM (1984) Functional considerations of the operation of GABAergic inhibitory processes in the visual cortex. In: The cerebral cortex, Vol 2A (Jones EG, Peters A, eds), pp 91-117. New York: Plenum.

Somogyi P, Freund TF, Halász N, Kisvárday ZF (1981) Selectivity of ncuronal [ $\left.{ }^{3} \mathrm{H}\right] \mathrm{GABA}$ accumulation in the visual cortex as revealed by Golgi staining of the labeled neurons. Brain Res 225:431-436.

Thalluri J, Henry GH (1989) Neurons of the striate cortex driven transsynaptically by electrical stimulation of the superior colliculus. Vision Res 29:1319-1323.

Toyama K, Kimura F, Tanaka K (1981a) Cross-correlation analysis of interneuronal connectivity in cat visual cortex. J Neurophysiol 46: 191-201.

Toyama K, Kimura F, Tanaka K (1981b) Organization of cat visual cortex as investigated by cross-correlation techniques. J Neurophysiol 46:202-214.

Ts'o DY, Gilbert CD, Wiesel TN (1986) Relationships between horizontal interactions and functional architecture in cat striate cortex as revealed by cross-correlation analysis. J Neurosci 6:1160-1170.

Weyand TG, Malpeli JG, Lee C, Schwark HD (1986) Cat arca 17. IV. Two types of corticotectal cells defined by controlling geniculate inputs. J Neurophysiol 56:1102-1108.

Zeki S (1983) Colour coding in the cerebral cortex: the reaction of cells in monkey visual cortex to wavelength and colours. Neuroscience 9:741-765. 